$\mathbb{P}$ periodica polytechnica

Mechanical Engineering

$52 / 2(2008) 67770$

doi: 10.3311/pp.me.2008-2.05

web: http://www.pp.bme.hu/me

(c) Periodica Polytechnica 2008

RESEARCH ARTICLE

\section{Pilot test and theoretical analysis of evaporation of one and more component fuels}

Tamás Laza

Received 2008-10-17

\begin{abstract}
The evaporation rate of different liquids was measured by exposing small droplets to an intensive radiative heat load. Several liquids were used namely water, 1-, 2-butanol, 1-, 2propanol, isobutanol and rape seed oil. A mixture of alcohol and rape seed oil (20/80 vol\%) was also analysed.

The sample results show the evaporation of different fractions of liquid for different wall temperatures and a constant counter flow of nitrogen.
\end{abstract}

\section{Keywords}

Renewable $\cdot$ rape seed oil $\cdot$ evaporation

\section{Acknowledgement}

Financial support has been partially provided by the Sapiens programme of the Portuguese Ministry of Science and Technology and Higher Education (POCTI/EME/45676/2002).

The author also acknowledges the financial support from GRICES and the Hungarian Science and Technology Foundation within the Portuguese-Hungarian Bilateral Intergovernmental SET Cooperation (4.1.1 OMFB / Port-17/03).

Tamás Laza

Department of Energy Engineering Engines, BME, H-1521 Budapest,, Hungary e-mail: laza@energia.bme.hu

\section{Introduction}

If reduction of $\mathrm{CO}_{2}$ emissions is intended, renewable energy sources is a prosperous way to follow. In previous publications it has been shown that rape seed oil can be used as an alternative fuel in gas turbines [1]. Among several problems, which still need to be solved the low vaporization rate of rape seed oil is object of a detailed analysis in the present study. For example, in the case of a gas turbine rape seed oil can be adhered to the wall of the combustion chamber. Therefore, either the combustor needs to be modified to avoid this problem or the physical properties of the liquid fuel need to be changed without compromising the use of rape seed oil as the main fuel.

Experimental measurements on real combustion application systems are expensive so computer simulation is needed. Nevertheless a lack of experimental data exists when rape seed oil and other bi-component fuels are considered.

\subsection{Measured fluids}

Some liquids are used in the present study: water, as a reference; n-heptane, as a pure fuel with several reported studies in the literature [2] [3], alcohols, namely: 1-, 2-butanol, 1-, 2propanol, isobutanol and rape seed oil. A mixture of alcohol and rape seed oil (20/80 vol\%) is also analysed.

Recent papers present that butanol instead of ethanol can be used as an additive to diesel oil. Mainly the phase separation, flash point decrease and inappropriate cold flow properties create the barriers for wide-spreading of this motor fuel type in the Central European climatic zone in case of ethanol [8]. On the other hand ethanol can not be mixed with rape seed oil, but butanol can.

The high viscosity of rape seed oil can cause problems during atomisation so reduction of viscosity is recommended. One way to achieve viscosity reduction is the esterification, but this process is expensive. The other way is the addition of a certain volume of alcohol (e.g. propanol and butanol) to the rape seed oil [5]. One further advantage of this bi-component mixture is that alcohol supports combustion, which was demonstrated by engines measuring the cetane number [7]. Howewer not only alcohol can be useful. The density and boiling points of several 


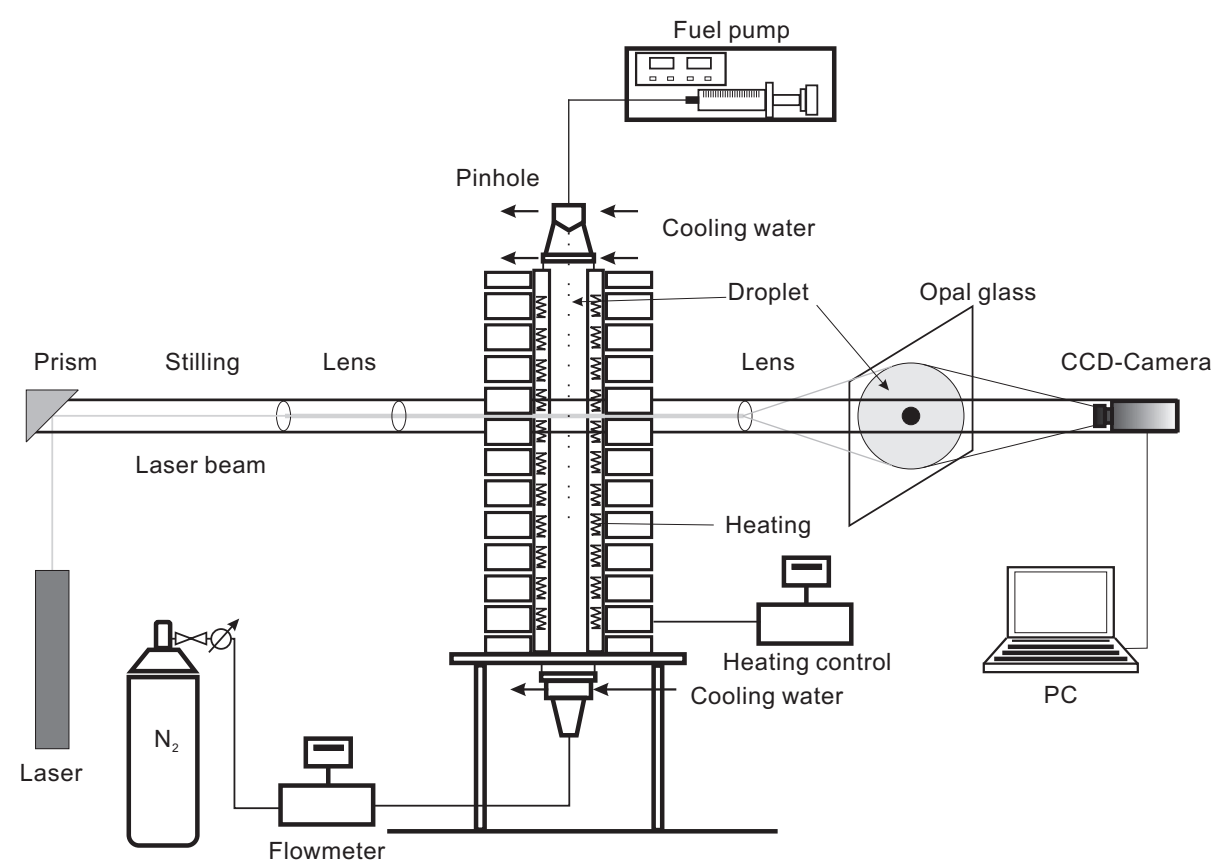

Fig. 1. Experimental facility and measuring system

liquids are shown in Table 1 .

Tab. 1. Characteristics of different liquids

\begin{tabular}{lccc}
\hline Material & $\begin{array}{c}\text { Density } \\
\mathrm{kg} / \mathrm{dm}^{3}\end{array}$ & $\begin{array}{c}\text { Boiling point } \\
{ }^{\circ} \mathrm{C}\end{array}$ & $\begin{array}{c}\text { Dyn. visc. } \\
\mathrm{mPa}^{*} \mathrm{~s}\end{array}$ \\
\hline Water & 0.99 & 100 & 1 \\
N-Heptane & 0.68 & 98 & 0.45 \\
Ethanol & 0.8 & 78.4 & 1.2 \\
Methanol & 0.79 & 64.5 & 0.54 \\
Kerosene jet-a & 0.799 & $155-260$ & $1.5-3$ \\
Rape seed oil & 0.96 & $300-600$ & $40-50$ \\
\hline
\end{tabular}

\section{Background}

The time derivative of the square of the droplet diameter is constant.

$$
K=\frac{d\left(d^{2}\right)}{d t}
$$

So we can find the time it takes a droplet of given initial size to completely evaporate [4].

The evaporation constant is independent of time, but it depends on the surface temperature, heat transfer conditions (flow velocity etc.) (see Table 2[4] [6]).

Tab. 2. The evaporation constant $\mathrm{K}\left[\mathrm{mm}^{2} / \mathrm{s}\right]$ of heptane, decane and dodecane

\begin{tabular}{lcccc}
\hline Ambient temp.: & \multicolumn{2}{c}{$300 \mathrm{~K}$} & $450 \mathrm{~K}$ & $800 \mathrm{~K}$ \\
Flow velocity: & $0 \mathrm{~m} / \mathrm{s}$ & $1.25 \mathrm{~m} / \mathrm{s}$ & $2 \mathrm{~m} / \mathrm{s}$ & $0 \mathrm{~m} / \mathrm{s}$ \\
\hline Heptane & 0.018 & 0.048 & 0.39 & $\mathrm{X}$ \\
Decane & 0.0012 & 0.0033 & 0.28 & $\mathrm{X}$ \\
Dodecane $\mathrm{t}_{d r}=480 \mathrm{~K}$ & $\mathrm{X}$ & $\mathrm{X}$ & $\mathrm{X}$ & 0.39 \\
$\mathrm{t}_{d r}=470 \mathrm{~K}$ & $\mathrm{X}$ & $\mathrm{X}$ & $\mathrm{X}$ & 0.256 \\
\hline
\end{tabular}

The evaluation of the evaporation constant is made by measurements. The schematic diagram of the experimental facility, installed at the Instituto Superior Técnico in Lisbon, is shown in Fig. 1 .

Measurements were performed in a vertical reactor tube which could be heated up to $700{ }^{\circ} \mathrm{C}$; evaporation of liquid droplets of different initial diameter was analysed. A droplet generator $(50 \mu \mathrm{m}$ pinhole $)$ and a needle $(0.7 \mathrm{~mm})$ were used.

Droplets enter the heated tube at the top of the reactor, through a water cooled cone, which also protects the droplet generator from the back flow of hot gas exiting the top of the reactor as nitrogen is fed at the bottom of the heating tube. The droplets in the heating tube are "intermittently" illuminated by a laser light cylinder and the image projected onto a screen. The liquid droplet image is captured by a high speed CCD camera. Image processing and analysis will allow to determine the evaporation characteristics of different liquids. An average sample of 50 images at each axial location is acquired for the droplet diameter calculation at the post-processing level, allowing for the determination of the evaporation rate.

The liquid droplets enter the reactor tube at environmental temperature and the first measurements are taken between the droplet generator, or needle, and the tube entrance.

In the case of rape seed oil and the mixture of rape seed oil and alcohol larger droplets are studied (1.8 and $4 \mathrm{~mm}$ ) by using a needle injection system instead of a droplet generator. This is due to the high surface tension and viscosity of the rape seed oil. Measurements were carried out at different wall temperatures, namely at $500{ }^{\circ} \mathrm{C}$ and $700{ }^{\circ} \mathrm{C}$.

It takes time to heat up the droplets. In Table 3 the achieved mean temperature of the droplet in the first and the seventh measuring line can be seen. 


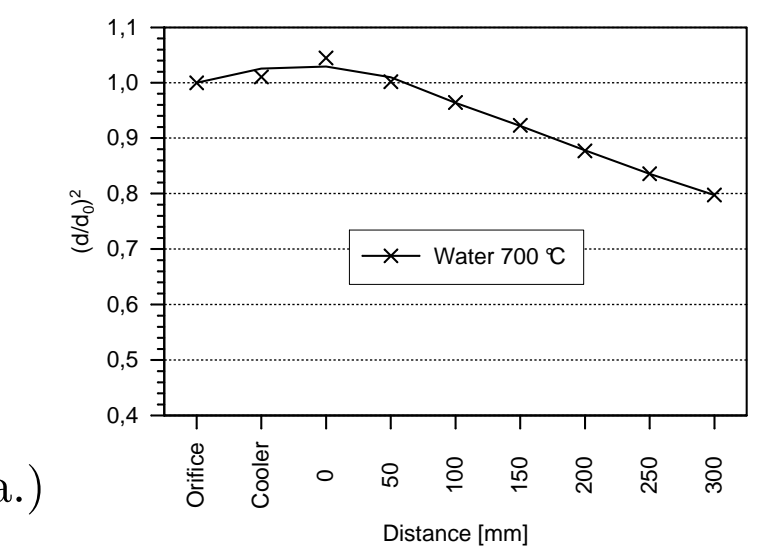

Fig. 2. Results of water: a) $\mathrm{d}_{o}=$ initial diameter at droplet generator exit (approx. $100 \mathrm{~mm}$ upstream the tube entrance); b) $\mathrm{d}_{m}=$ maximal diameter just

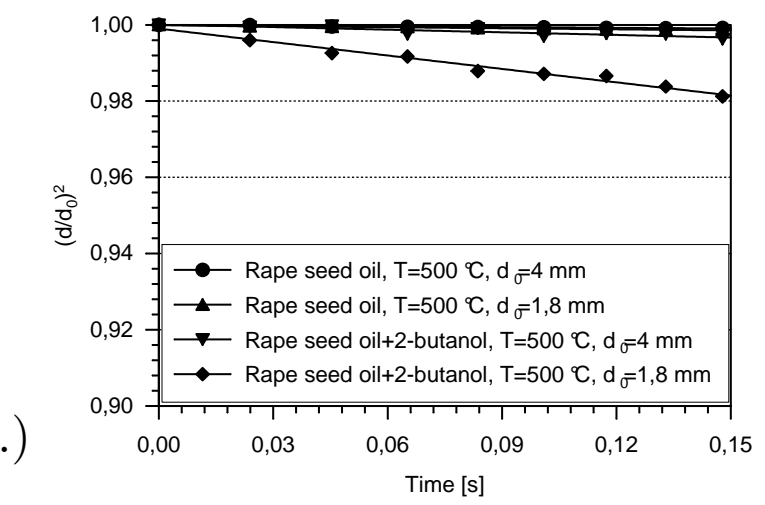

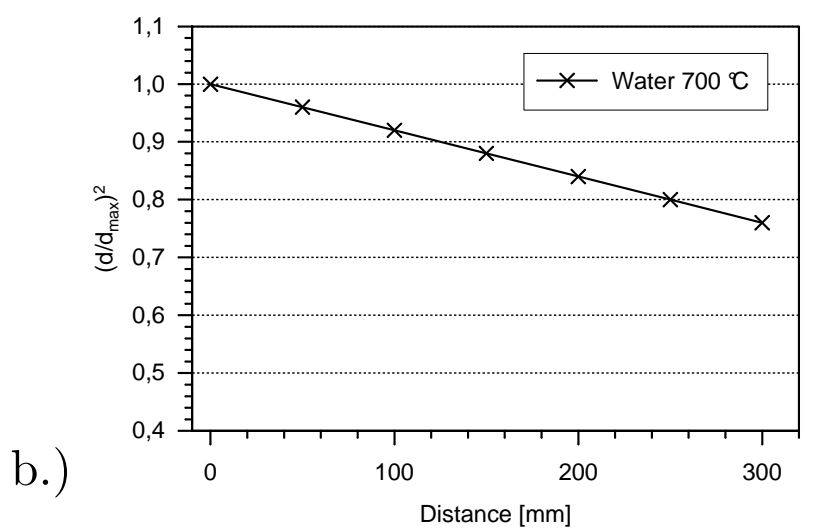

before the tube entrance

b.)

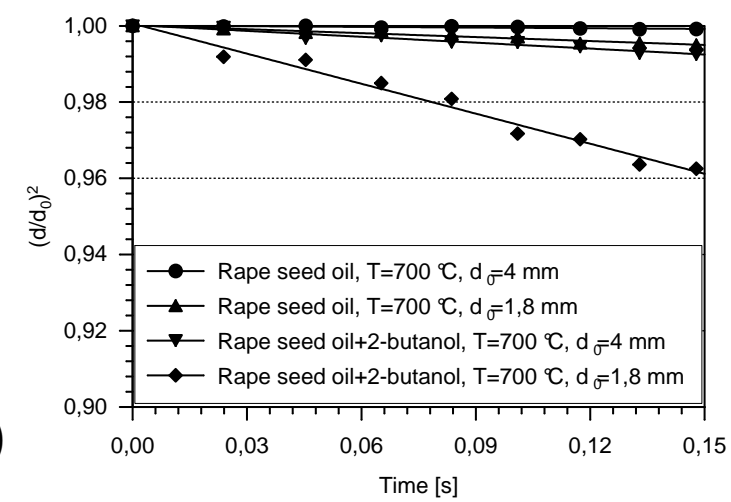

Fig. 3. Results of pure rape seed oil and rape seed oil + 1-butanol, at a.) 500 and b.) $700{ }^{\circ} \mathrm{C}$

Tab. 4. Determination of the evaporation constant of rape seed oil + butanol mixture. The results marked with * have a large relativ error.

\begin{tabular}{|c|c|c|c|c|c|c|c|}
\hline Temperature & $\begin{array}{c}\mathrm{d}_{0} \\
{[\mathrm{~mm}]}\end{array}$ & $\left(\mathrm{d} / \mathrm{d}_{0}\right)^{2}$ & $\begin{array}{c}\text { Time } \\
{[\mathrm{s}]}\end{array}$ & $\begin{array}{c}\mathrm{K} \\
{\left[\mathrm{mm}^{2} / \mathrm{s}\right]}\end{array}$ & $\left(\mathrm{d} / \mathrm{d}_{0}\right)^{2}$ & $\begin{array}{c}\text { Time } \\
\text { [s] }\end{array}$ & $\begin{array}{c}\mathrm{K} \\
{\left[\mathrm{mm}^{2} / \mathrm{s}\right]}\end{array}$ \\
\hline & & \multicolumn{3}{|c|}{ Rape seed oil } & \multicolumn{3}{|c|}{ Solution } \\
\hline 500 & 1.8 & $0.998^{*}$ & 0.147 & $0.06^{*}$ & 0.97 & 0.147 & 0.56 \\
\hline 500 & 4 & $0.999^{*}$ & 0.147 & $0.08^{*}$ & 0.995 & 0.147 & 0.54 \\
\hline 700 & 1.8 & 0.999 & 0.147 & 0.108 & 0.962 & 0.147 & 0.82 \\
\hline 700 & 4 & 0.995 & 0.147 & 0.109 & 0.992 & 0.147 & 0.81 \\
\hline
\end{tabular}

Tab. 3. Calculated mean temperature $\left[{ }^{\circ} \mathrm{C}\right]$ of rape seed oil in the first and seventh measuring line

\begin{tabular}{cccc}
\hline \multirow{2}{*}{ Diameter } & Ambient temp.: & $500{ }^{\circ} \mathrm{C}$ & $700{ }^{\circ} \mathrm{C}$ \\
\cline { 2 - 4 } & Measuring line & \multicolumn{2}{c}{ Mean droplet temp. ${ }^{\circ} \mathrm{C}$} \\
\hline \multirow{2}{*}{$1.8 \mathrm{~mm}$} & 1. & 87 & 115 \\
& 7. & 102 & 136 \\
\hline \multirow{2}{*}{$4 \mathrm{~mm}$} & 1. & 42 & 50 \\
& 7. & 46 & 55 \\
\hline
\end{tabular}

\section{Results and discussion}

Fig. 2 shows the vaporisation characteristics of water droplet for a wall temperature of $700{ }^{\circ} \mathrm{C}$ and a nitrogen flow corresponding to a mean axial velocity of $0.3 \mathrm{~m} / \mathrm{s}$.

Fig. 2 a shows the diameter of the droplet leaving the droplet generator made non-dimensional by the initial droplet diame- ter; the first measured axial location is at the droplet generator exit. Therefore, the droplet heating up process can be followed. Fig. $2 \mathrm{p}$ shows the same results but made non-dimensional by the maximum droplet diameter measured. It can be seen that, in this case, the diameter is continuously decreasing.

No significant diameter change occured for smaller $(1.8 \mathrm{~mm})$ and larger $(4 \mathrm{~mm})$ pure vegetable oil droplets during the free fall time at $500{ }^{\circ} \mathrm{C}$ wall temperature (see Fig. 3a). Some diameter reduction can be noticed for the smaller droplets. The gradient of the graph depends on the initial diameter of the droplet. Although a larger diameter shows a lower gradient in the graph it has the same evaporation constant as small droplet because it takes more time for a larger droplet to evaporate than it does for a smaller one. (In Figs. 2 and 3 the time variation of $\left(d / d_{0}\right)^{2}$ is shown while the evaporation constant $\mathrm{K}$ has been defined as $\left.\mathrm{d}\left(d^{2}\right) / \mathrm{d} t\right)$. 
At $500{ }^{\circ} \mathrm{C}$ the diameter of the droplets of solution of rape seed oil and 2-butanol decreases significantly. The droplets evaporate continuously with a constant speed no slope change can be seen.

The exhalation of the 2-butanol does not stop in the measuring range because of the large droplet diameter. For larger droplets the warming up, the alcohol's diffusion to the surface and evaporation needs more time at lower temperature. It can be noticed, that the graphs based on the results are not linear as theoretically would be expected. This can be explained by the two opposite effects of initial volume growth caused by warming up and the intensified evaporation rate of the increased droplet size, balancing each other. A further uncertainty is given by measurement errors.

At $700{ }^{\circ} \mathrm{C}$ the evaporation of the pure rape seed oil is measurable. Apart from smaller fluctuations the gradient of the graph is relatively constant in the measuring range. The decreasement of the square of the relative diameter in case of 2-butanol - rape seed oil mixture is faster, and the measuring range is not enough to the complete evaporation of the alcohol. The initial diameter is too high in this temperature range. It is noticeable that the diffusion needs more time for larger droplets and after this time they still contain alcohol.

The evaporation constants registered at different temperatures can be calculated from the results. See data in Table 4

The results show that the evaporation constant of the pure rape seed oil is about 10 times smaller than that of the solution. The evaporation constant of larger droplets seems to be higher. This can be caused by the measuring errors. At this temperature the evaporation was not significant enough for an accurate size determination (the difference betwen the initial and the final diameter was just a few pixels) and the errors in the measurements were relatively high. In case of the solution the alcohol content increases the speed of evaporation. It can be said that the difference between the evaporation constants of smaller and larger droplets is low.

\section{Conclusion}

Although the generally used small droplets which are typical for combustion purposes can not be generated, the results are valuable in observing the initial stage of evaporation and in later validating computer simulation results.

The evaporation constant of the rape seed oil and different rape seed oil - alcohol mixtures were determined by measurements. The evaporation of rape seed oil at $500{ }^{\circ} \mathrm{C}$ was hardly but at $700{ }^{\circ} \mathrm{C}$ well detectable. In the case of alcoholic mixtures the evaporation of alcohol is very fast therefore the result can be accepted only for the initial stage of the evaporation.

\section{References}

1 Laza T, Penninger A, Koch R, Analyse der Oszillation eines rapsölbetriebenen Kleingasturbinenbrenners, Braunschweig, 2005. 22. Deutscher Flammentag.
2 Elperin T, Krasovitov B, Radiation, thermal diffusiond kinetic effects in evaporation and combustion of large and moderate size fuel droplets, Int. J. Heat Mass Transfer 38 (1995), no. 3, 409-418, DOI 10.1016/00179310(94)00168-U.

3 Lavieille $\mathbf{P}$, Lemoine $\mathbf{F}$, Lebouché $\mathbf{M}$, Investigation on Temperature of Evaporating Droplets in Linear Stream Using Two-Color LaserInduced Fluorescence, Combust. Sci. Tech. 174 (2002), 117-142, DOI 10.1080/713713017

4 Turns S R, An Introduction to Combustion - Concepts and Applications, McGraw-Hill Book Co., Singapore, 1996.

5 Laza T, Penninger A, Viscosity of rape seed oil and higher alcohol mixtures, Energiagazdálkodás Ann. 46 (2005), no. 5.

6 Goekalp I, Chauveau C, Berrekam H, Examination of Burning Processes of Regenerative Liquid Fuel and Alcohol Mixtures in Diesel Engine, Combust. Sci. and Tech. 174 (1994), 117-142.

7 Bereczky Á, Meggyes A, Laza T, Kecskés R, Vaporization of miscible binary fuel droplets under laminar and turbulent convective conditions, International Conference on Heat Engines and Environmental Protection, Balatonfüred, 2005.

8 Bratsky D, Stacho D, Will Ethanol be Replaced by Buthanol?, 2nd Central European Biomass Conference, Graz, 2008. 